\title{
ARTIFICIAL PACEMAKING AND SINUS RHYTHM
}

\author{
BY
}

\author{
EDGAR SOWTON
}

From the Cardiac Department, St. George's Hospital, London S.W.1, and the Institute of Cardiology, London W.1

Received June 18, 1964

The use of artificial pacemakers in the treatment of patients with complete heart block is now well established but there is still doubt as to whether this type of therapy should be used in patients with intermittent A-V conduction. This paper reports clinical experience and hæmodynamic investigation in 16 patients with A-V conduction and artificial pacemakers.

\section{SubJeCtS AND MethodS}

The patients reported form part of a larger series of 60 patients with Stokes-Adams disease treated with artificial pacemakers, which is being reported in full elsewhere. The series contained 32 men between the ages of 39 and 81 , and 28 women between 27 and 76 . There was a bias towards the older age-groups with 53 per cent of the men and 62 per cent of the women being over 65 years. No patients with heart block following cardiac surgery have been included in this series.

Artificial pacing was achieved by means of an electrode catheter passed to the right ventricle from a peripheral vein, the heart being driven by a small adjustable pacemaker (Davies, 1962). Exercise studies were carried out on a bicycle ergometer, electrocardiograms were taken on a Cambridge photographic recorder, and cardiac output was measured by a dye dilution technique using Coomassie blue as described in a previous publication (Sowton, 1964a).

\section{Clinical Results}

Two of the 60 patients were in sinus rhythm at the time artificial pacing was started. Of the remaining 58 patients, $14(23 \%)$ reverted to sinus rhythm shortly after pacing had started; this change occurred in most patients within one week and in $12(20 \%)$ within one day. When A-V conduction returned, the sino-atrial (S-A) node competed with the artificial pacemaker for control of the heart rate and the resulting rhythm depended on the comparative rates of the two foci. When the artificial pacemaker rate was considerably faster than the sinus rate, sinus rhythm was usually suppressed and the atrium contracted after the start of ventricular systole due to retrograde conduction along the bundle of His (Fig. 1). The conduction time in these patients was identical for prograde and retrograde conduction as previously noted by Linenthal et al. (1962). When the sinus rate was considerably faster than that of the artificial pacemaker parasystole was produced (Fig. 2) (Zoll, 1952; Nuñez-Dey, Zalter, and Eisenberg, 1962). When the artificial and sinus pacemakers were firing at similar rates a cyclical phenomenon was often seen in which control was obtained alternately by each pacemaker (Fig. 3). This pattern suggests the phenomenon of "interference beats", well recognized in other fields (physics, music, electronics), and indicates that the S-A node is capable of rhythmical activity at a steady rate even when no atrial or ventricular contraction results. A theoretical treatment of this type of cyclical interference has been given elsewhere (Sowton, 1964b). 
FIG. 2.-Electrocardiogram of a patient with A-V conduction being paced from the ventricle with resultant parasystole. The pacemaker markers indicate each stimulus deflection. The sinus rhythm markers indicate $P$ waves.

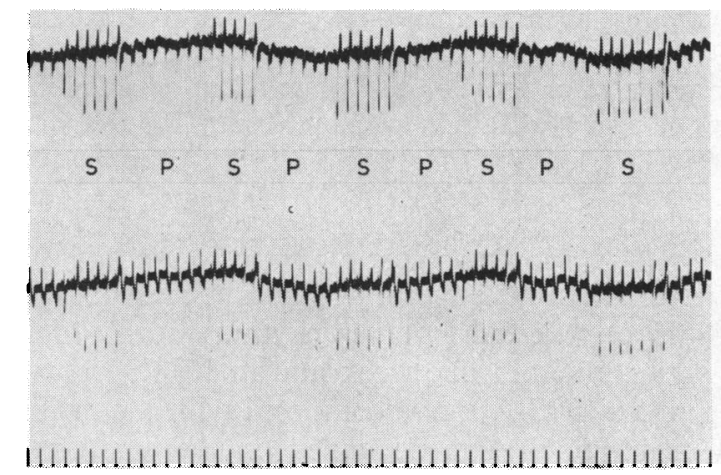

Fig. 3.-Electrocardiogram showing cyclical interference between sinus rhythm and an artificial pacemaker rhythm. $\mathbf{S}=$ sinus rhythm. $\mathbf{P}=$ paced rhythm. Time markers (bottom line) 1 sec. apart. Leads I and III.

The presence of parasystole allowed the pacemaker stimulus to fall in the vulnerable period of the cardiac cycle during the sinus beats, a situation that occurred in these patients about twice a minute or approximately 3000 times a day. An analysis of the rhythm of 58 patients who had long-term pacemakers inserted more than six months ago gave the results shown in Table I. The group of patients with parasystole did not differ significantly from the whole, except that the death rate amongst patients with parasystole was five times that amongst patients with paced rhythm only, a highly significant result $(0.01>\mathrm{p}>0.001)$. 
TABLE I

Comparison of Patients with and without Parasystole during Artificial Pacemaking

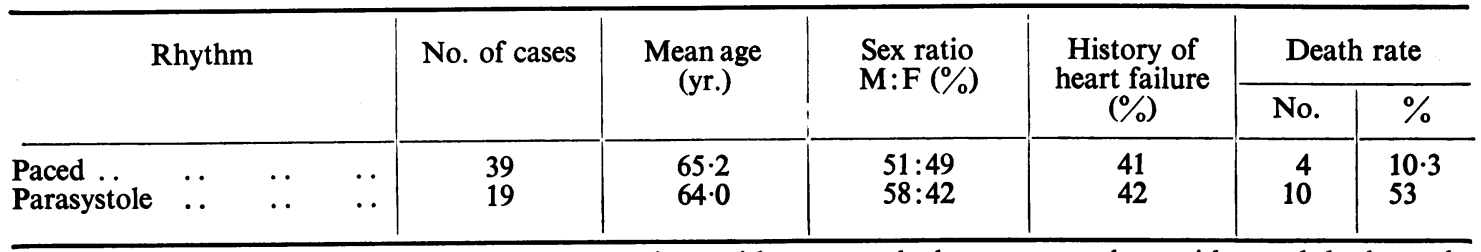

The death rate was five times higher amongst patients with parasystole than amongst those with paced rhythm only.

TABLE II

Arrhythmias Developing during Stable Pacemaking

\begin{tabular}{|c|c|c|c|c|c|c|}
\hline $\begin{array}{l}\text { Patient } \\
\text { No. }\end{array}$ & Sex & Age & Rhythm while pacing & $\begin{array}{l}\text { Rhythm in } \\
\text { attack }\end{array}$ & Time of attack & Result \\
\hline 1 & $\mathbf{M}$ & 67 & $\begin{array}{l}\text { Parasystole from sinus } \\
\text { rhythm }\end{array}$ & VF & 36 hours post-op. & Died \\
\hline 2 & $\mathbf{M}$ & 67 & $\begin{array}{l}\text { Parasystole from sinus } \\
\text { rhythm }\end{array}$ & VF & 36 hours post-op. & Died* \\
\hline 3 & $\mathbf{M}$ & 55 & $\begin{array}{l}\text { Parasystole from two } \\
\text { pacemakers }\end{array}$ & $\begin{array}{l}\text { VF } \\
(\times 2)\end{array}$ & 48 and 52 hours post-op. & Died \\
\hline 4 & $\mathbf{F}$ & 61 & $\begin{array}{l}\text { Parasystole from idio- } \\
\text { ventricular rhythm }\end{array}$ & VF & $\begin{array}{l}7 \text { days after start of } \\
\text { pacing }\end{array}$ & Recovered \\
\hline 5 & $\mathbf{M}$ & 72 & $\begin{array}{l}\text { Parasystole from sinus } \\
\text { rhythm }\end{array}$ & VF & 18 hours post-op. & Died \\
\hline 6 & $\mathbf{M}$ & 66 & $\begin{array}{l}\text { Parasystole from sinus } \\
\text { rhythm }\end{array}$ & $\begin{array}{l}\text { VT } \\
(\times 2)\end{array}$ & 36 and 40 hours post-op. & Recovered \\
\hline
\end{tabular}

* Necropsy showed 10-day-old cardiac infarct.

Nine-volt stimulus via electrode catheter in coronary sinus. Necropsies on Patients 1, 3, and 5 disclosed clear coronary arteries: no cause for death was found and no electronic or wire failure could be discovered.

$\mathrm{VF}=$ ventricular fibrillation; VT = ventricular tachycardia.

During stable pacemaking while in hospital, 5 patients developed ventricular fibrillation, observed on an oscilloscope electrocardiograph monitor or recorded on a direct writing electrocardiograph machine, and one developed rapid ventricular tachycardia. Details of these patients are shown in Table II. All 6 patients were in parasystole at the time of their collapse which occurred in the early post-operative period in five instances.

\section{HAMODYNAMIC INVESTIGATIONS}

In one patient it was possible to produce "beats" between the artificial pacemaker and the sinus pacemaker, in which each captured the rhythm for 30 to 40 seconds, long enough for cardiac output measurements to be made during each phase of the cycle, and the results of this investigation are shown in Table III.

The mean output during sinus rhythm was $4.51 . / \mathrm{min}$. and the mean output during ventricular pacing was 3.41 . $/ \mathrm{min}$, a drop of 25 per cent. This was, of course, an immediate change and there was no opportunity for compensating mechanisms to come into play, because sinus rhythm was rapidly re-established after each period of pacing.

TABLE III

Cardiac Output during Cyclical Rhythm Changes

\begin{tabular}{|c|c|c|c|c|c|c|c|}
\hline & Rhythm & & Sinus & Paced & Sinus & Paced & Sinus \\
\hline Cardiac output & $\left\{\begin{array}{l}\text { Litres/min. } \\
\text { Relative flow .. }\end{array}\right.$ & $\begin{array}{l}\ldots \\
\ldots\end{array}$ & $\begin{array}{c}4 \cdot 3 \\
100 \%\end{array}$ & $\begin{array}{c}3 \cdot 2 \\
74 \%\end{array}$ & $\begin{array}{l}4 \cdot 6 \\
107 \%\end{array}$ & $\begin{array}{l}3 \cdot 5 \\
81 \%\end{array}$ & $\begin{array}{l}4 \cdot 5 \\
104 \%\end{array}$ \\
\hline
\end{tabular}

Pacemaker rate 81 beats $/ \mathrm{min}$. throughout. 
TABLE IV

Cardiac Output with and without Atrial Contribution

\begin{tabular}{c|c|l|c|c}
\hline $\begin{array}{c}\text { Measurement } \\
\text { No. }\end{array}$ & $\begin{array}{c}\text { P-R interval } \\
\text { (sec.) }\end{array}$ & \multicolumn{1}{|c|}{ Time of measurement } & \multicolumn{2}{|c}{ Cardiac output } \\
\cline { 4 - 5 } & $\mathbf{0 . 2}$ & Steady state & $1 . / \mathrm{min}$. & $\%$ flow \\
\hline 1 & 0.0 & Immediately following change & 2.8 & 100 \\
2 & $\mathbf{0 . 0}$ & New steady state & 3.9 & 97 \\
\hline
\end{tabular}

Pacemaker rate 90 beats/min. throughout.

Atrial function was investigated in another patient by pacing the ventricle through wires attached surgically at a previous operation and pacing the atrium via an electrode catheter, with a pacemaker that produced two stimuli with an adjustable delay. In this patient it proved impossible to pace the heart at a slower rate than 90 beats a minute as atrial escape occurred. Cardiac output was initially measured at rest with a delay time ("P-R interval") of 0.2 sec., and the delay was then rapidly shortened to zero which resulted in the atrium contracting against a closed A-V valve, and so produced a sudden loss of atrial delivery. Cardiac output measurements were made immediately and again some seven minutes later with no change in external conditions, the patient sitting comfortably at rest and the heart rate remaining unaltered throughout. The results are shown inTable IV.

The sudden loss of atrial contribution caused a fall of 30 per cent in cardiac output but changes in ventricular stroke volume over the next few minutes returned the output to its original level despite the absence of atrial delivery. This investigation was curtailed because of the development of atrial flutter when an attempt was made to pace the atrium below 90 beats a minute, but a final measurement of cardiac output about 6 minutes after the onset of this arrhythmia showed the flow to be just under 41 ./min., a figure very close to the original measurement, suggesting that the output had been maintained by adjustments of ventricular stroke volume. Normal atrial contraction returned spontaneously after a few minutes, but the technique of atrial and ventricular pacing has not been applied clinically because of the risk of provoking atrial arrhythmias.

Rate-output curves at rest were obtained in 3 patients with sinus rhythm, the cardiac output being measured 4 minutes after the change of pacemaker rate (Sowton, 1964b), with the patients lying semi-horizontal and propped up on pillows. The curves were of the form illustrated in Fig. 4. These 3 patients were also investigated during exercise and rate-output curves of the type illustrated in Fig. 5 were obtained. The exercise level for this investigation was low ( 20 watts) because it was

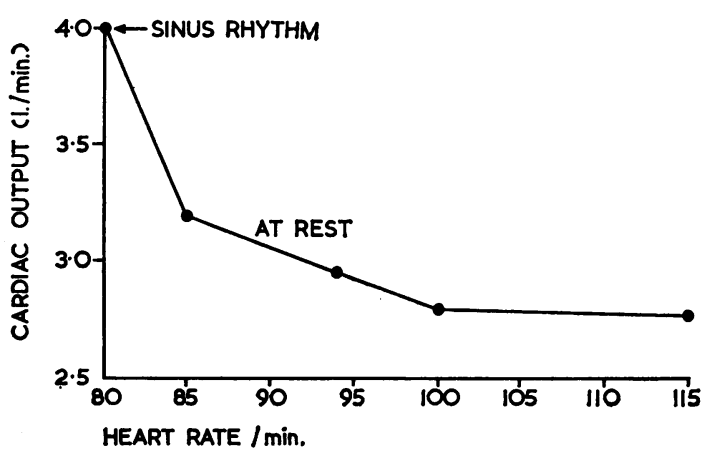

FIG. 4.-Rate-output curve with measurements made 4 minutes after each change in pacemaker rate. The initial cardiac output measurement was made with the patient in sinus rhythm. Subsequent measurements were made during ventricular pacing.

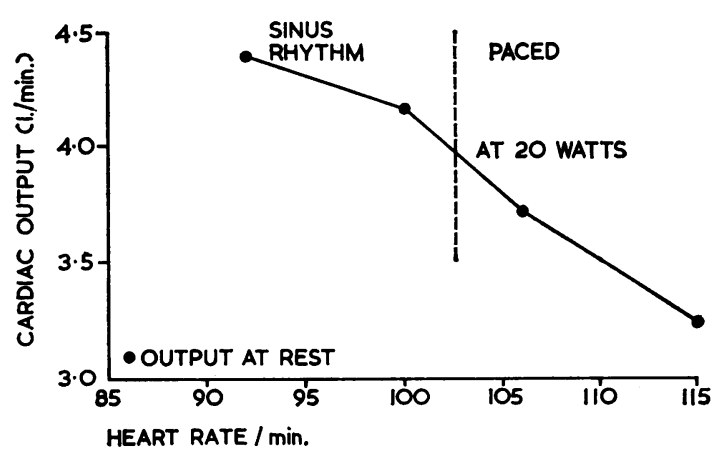

FIG. 5.-Rate-output curve during steady exercise (power produced 20 watts). The first cardiac output measurement was made with the patient in sinus rhythm. Subsequent measurements were made during ventricular pacing. The output in sinus rhythm at rest is shown for comparison. 


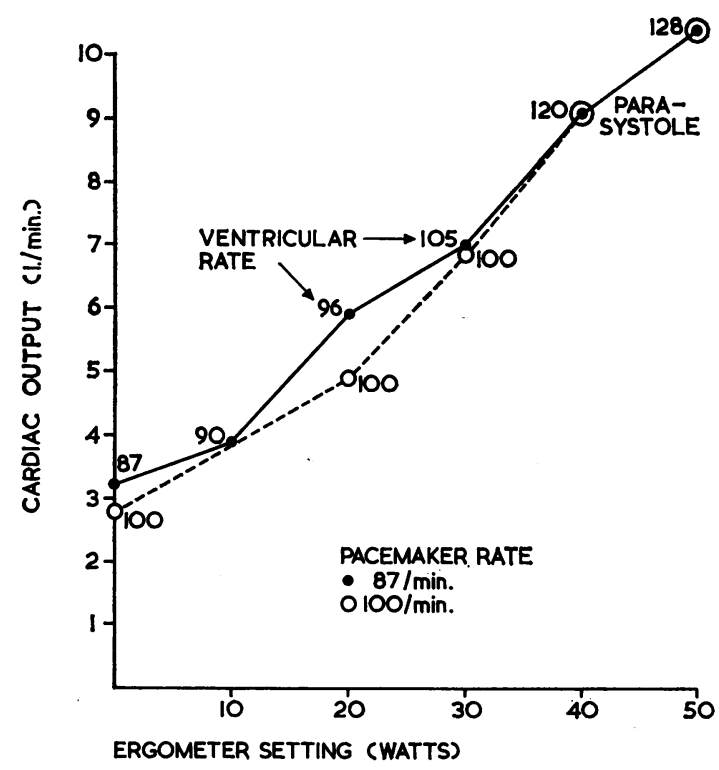

FIG. 6.-Effect of increasing work loads during parasystole from sinus rhythm and ventricular artificial pacing. Two output-power curves are shown with the pacemaker at fixed rates of 87 beats a minute and 100 beats a minute. When the sinus rate exceeded the pacemaker rate the resultant ventricular rate was the same for each investigation. Cardiac output was related to the power produced and not to the pacemaker settings.

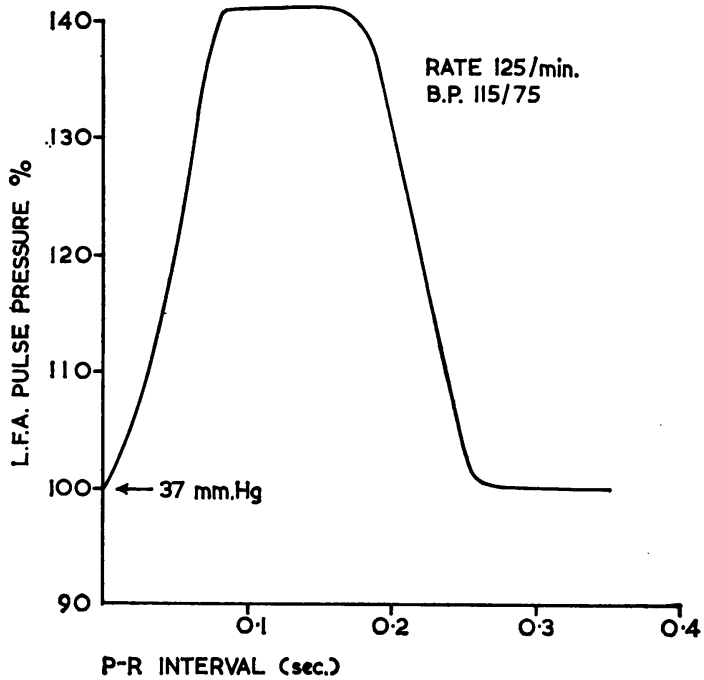

FIG. 7.-P-R interval plotted against the mean left femoral artery pulse pressure for the corresponding beats. A pulse pressure of $37 \mathrm{~mm}$. $\mathrm{Hg}(100 \%)$ corresponded to ventricular contractions without atrial contribution. The mean blood pressure throughout the investigation was $115 / 75 \mathrm{~mm}$. $\mathrm{Hg}$. The pulse pressure was increased by 40 per cent during physiological placing of atrial contraction.

necessary for the patients to continue steady state exercising for about 30 minutes. The patient whose results are illustrated, a 66-year-old man, weighing $58 \mathrm{~kg}$., increased his output from a resting control level of $3.1 \mathrm{l} . / \mathrm{min}$. at a sinus rate of 86 beats a minute to $4.41 . / \mathrm{min}$. at a sinus rate of 92 beats a minute during exercise. The pacemaker was then switched on and cyclical interference followed until sinus rhythm was completely suppressed at a pacemaker rate of about 102 beats a minute. As the pacemaker rate was increased his cardiac output fell and he was unable to continue exercise when his ventricular rate was above 115 beats a minute.

Further studies during exercise were carried out on this patient who was asked to pedal on the bicycle ergometer during increasing work loads while the pacemaker rate was held constant, initially at 87 beats a minute but during a second investigation at 100 beats a minute; these rates were fast enough to suppress sinus rhythm at rest but parasystole appeared during exercise. The cardiac output was measured at rest and at each of five work loads for both pacemaker rates. The two powercardiac output curves followed each other closely as shown in Fig. 6. An attempt was made to repeat the investigation with a pacemaker setting of 130 beats a minute but the patient's exercise tolerance with this ventricular rate was so poor that he was unable to reach even 15 watts on the ergometer.

The effect of the timing of atrial systole was studied by plotting the beat-by-beat pressure in the femoral artery against the corresponding $\mathbf{P}-\mathrm{R}$ interval in a patient with complete heart block being paced from the right ventricle; the pulse pressure has been plotted rather than the systolic pressure in order to minimize variations due to respiration (Fig. 7). The mean blood pressure was 115/75 $\mathrm{mm}$. $\mathbf{H g}$, but the pulse pressure increased by 40 per cent when the $P-R$ interval fell within physiological limits. The shape of the graph altered a little with pacemaker rate, the descending limb becoming less steep as the rate decreased, but it was obvious that the most effective timing for atrial 


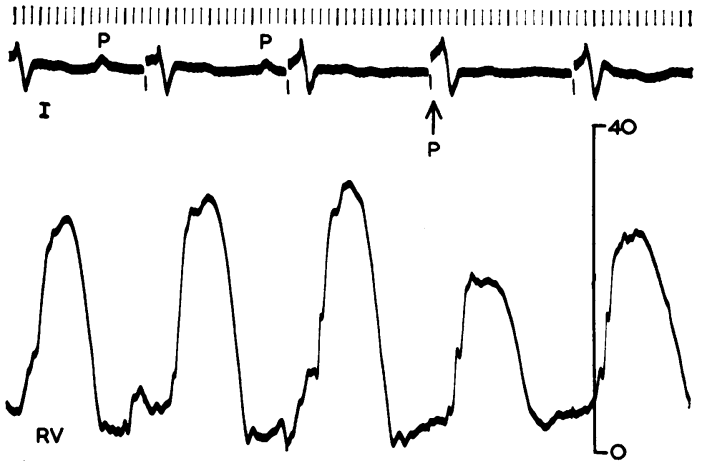

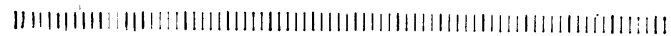

FIG. 8.-Right ventricular pressure tracings recorded during artificial pacing of the ventricle in a patient with complete heart block. The systolic pressure is low when the $\mathbf{P}$ wave is buried in the QRS. Time markings 0.2 and $0.04 \mathrm{sec}$. contraction was that corresponding to normal sinus rhythm, and this conclusion is supported by similar reports from Johansson and his co-workers in Malmo (1963) and B. Jonsson, S. Bevegård, and I. Karlöf in Stockholm (personal communication, 1964). A similar effect was noted in the right ventricular pressure trace of one patient where a lower pressure was produced when the $P$ wave was buried in the QRS complex (Fig. 8.)

\section{Discussion}

The use of artificial pacemakers in patients with A-V conduction results in two distinct problems. First, the risk of pacemaker-induced ventricular fibrillation caused by the stimulus falling in the vulnerable period of the cardiac cycle (Wiggers and Wégria, 1940) and secondly the hæmodynamic problems associated with parasystole. Opinion is divided as to the possibility of pacemaker-induced fibrillation, several authors feeling that the risk is minimal (Chardack, Gage, and Greatbatch, 1961; Johansson et al., 1963; Zoll and Linenthal, 1960) while other workers feel that considerable risk is involved (Dittmar, Friese, and Holder, 1962; Lillehei et al., 1963). It is apparent that the risk should be much higher during parasystole than when stable pacing is occurring, as in the latter case the pacemaker stimulus could fall in the vulnerable period only during occasional ventricular ectopic beats, and Chardack et al. (1961) have shown that ventricular fibrillation can be experimentally produced in dogs by adjustment of the pacemaker rate to produce parasystole. The results reported here strongly suggest that the difference in death rate between patients with and without parasystole was due to pacemaker-induced ventricular fibrillation, and this view is supported by the experience of L. Abrams (1963, personal communication) who has also noted the development of sudden ventricular fibrillation in the early post-operative period in patients with A-V conduction. The risk appears particularly high in the early post-operative period, and it is possible that the threshold for ventricular fibrillation is lowered by the inflammatory reaction around the site of attachment of the electrodes to the heart. It has been shown that the fibrillation threshold can be lowered nearly to the stimulation threshold by adrenaline, sympathomimetic drugs, anæsthetic agents, or ischæmia (Brooks et al., 1955; Bonnabeau et al., 1963), and several of these factors may be present after operation in patients with Stokes-Adams disease. The pacemakers originally used in this study gave impulse energies of about 200 micro-joules, and the stimuli were thus ten times the threshold value (Davies and Sowton, 1964); the apparatus has since been modified to deliver stimuli at lower energy levels (J. G. Davies, 1963, personal communication). As approximately one-quarter of the patients in this series returned to sinus rhythm shortly after artificial pacemaking was started and so were at risk to develop ventricular fibrillation caused by the pacemaker, there is a case for the prophylactic use of procaine amide for the first few post-operative days, while all sympathomimetic drugs should be stopped as soon as pacing is established. The development of pacemakers that are temporarily inhibited by a preceding spontaneous ventricular contraction (Nicks, Stening, and Hulme, 1962), or in which the pacing stimulus is triggered from the atrium (Lillehei et al., 1963; Nathan et al., 1963), offer elegant methods of avoiding stimulation during the vulnerable period at the expense of an increase in complexity of the electronic apparatus.

The second problem to be considered concerns the hæmodynamic effects of the loss of atrial contribution and of parasystole during ventricular pacing, and in these respects the present results 
are in agreement with the opinion expressed by Zoll and his co-workers (1961), showing that an adequate circulation could be maintained during all conditions of ventricular pacing with A-V conduction.

The present investigations related to the synchronization of atrial and ventricular contraction indicate that the sudden loss of atrial delivery causes an immediate drop in cardiac output of about 25-30 per cent at rest, and these results are compatible with those of early investigators (Gesell, 1915; Wiggers and Katz, 1922) as well as with the findings of Sellers, Donald, and Wood (1962) who used two electrode catheters to achieve atrial and ventricular pacing in dogs with denervated hearts and showed a 15 per cent increase in cardiac output when atrial systole was correctly timed. Similar observations on the effects of altering the atrial delivery and the timing of atrial contraction have been made by Sarnoff's group who used dog heart preparations with multiple sites for pacing electrodes to show that when the ventricle was deprived of the atrial contribution the end-diastolic pressure was lower and the ventricle produced less external work, while a properly timed effective atrial contraction enhanced ventricular filling and could close the atrio-ventricular valve (Gilmore et al., 1963; Skinner et al., 1963). The present results indicate that when the heart rate is held constant by an artificial pacemaker there is an immediate drop in cardiac output following the loss of atrial delivery, but alterations in ventricular stroke volume return the cardiac output to its original level over the next few minutes. This result is analogous to those found when cardiac output is altered by sudden changes in the rate of an artificial pacemaker (Sowton, 1964a), by injection of atropine (Berry et al., 1959), or by the development of a tachycardia (Bevegård, 1962; Saunders and Ord, 1962), and is in agreement with the common clinical observation that most patients with atrial fibrillation experience little or no disability at rest. The alterations in the systemic blood pressure produced by variations in timing of atrial systole are in agreement with reports by other workers (Johansson et al., 1963; Samet et al., 1963), and demonstrate that physiological placing of atrial systole produces a considerable immediate increase in the pulse pressure. It remains to be shown that there is a long-term improvement in hæmodynamic function from synchronized pacemaking.

\section{SUMmaRY AND CONCLUSIONS}

In a series of 60 patients with Stokes-Adams disease treated by artificial pacing A-V conduction returned in about 25 per cent.

In the patients in whom A-V conduction returned, and who were treated by ventricular pacemaking, parasystole developed; hæmodynamic function was then equal to, or better than, that achieved by ventricular pacing alone but the risk of sudden death was greatly increased. This was probably due to the development of ventricular fibrillation triggered by a high-energy pacemaking stimulus falling during the vulnerable period of the cardiac cycle, and the risk of this arrhythmia appeared to be at its maximum during the early post-operative period.

With the patient at rest the sudden loss of atrial contribution to ventricular filling caused an immediate fall in cardiac output of about 25 per cent. Subsequent changes in ventricular stroke volume returned the output to its initial level, despite a constant heart rate.

The most effective timing of atrial systole as judged acutely by the systemic or R.V. pressure was that corresponding to a physiological P-R interval.

Most of the patients were under the care of Dr. Aubrey Leatham, and my thanks are due for his encouragement. I am grateful also to Mr. A. H. M. Siddons for permission to investigate his patients and to Mr. J. G. Davies for technical assistance.

This paper is based on work included in a thesis for the M.D. degree of the University of Cambridge.

\section{REFERENCES}

Berry, J. N., Thompson, H. K., Jr., Miller, D. E., and McIntosh, H. D. (1959). Changes in cardiac output, stroke volume, and central venous pressure induced by atropine in man. Amer. Heart J., 58, 204.

Bevegård, S. (1962). Studies on the regulation of the circulation in man. Acta physiol. scand., 57, Suppl. 200. 
Bonnabeau, R. C., Bilgutay, A. M., Sterns, L. P., Wingrove, R., and Lillehei, C. W. (1963). Observations on sudden death during pacemaker stimulation in complete atrioventricular block. Trans. Amer. Soc. Artificial Internal Organs, 9, 158.

Brooks, C. McC., Hoffman, B. F., Suckling, E. E., and Orias, O. (1955). Excitability of the Heart. Grune and Stratton, New York.

Chardack, W. M., Gage, A. A., and Greatbatch, W. (1961). Correction of complete heart block by a self-contained and subcutaneously implanted pacemaker. J. thorac. cardiovasc. Surg., $42,814$.

Davies, J. G. (1962). Artificial cardiac pacemakers for the long-term treatment of heart block. J. Brit. Instn Radio Engrs, 24, 453.

- , and Sowton, E. (1964). Cardiac pacemakers. Phys. Med. Biol., 9, 257.

Dittmar, H. A., Friese, G., and Holder, E. (1962). Erfahrungen über die langfristige elektrische Reizung des menschlichen Herzens. Z. Kreisl.-Forsch., 51, 66.

Gesell, R. (1915). The effects of change in auricular tone and amplitude of auricular systole on ventricular output. Amer. J. Physiol., 38, 404.

Gilmore, J. B., Sarnoff, S. J., Mitchell, J. H., and Linden, R. J. (1963). Synchronicity of ventricular contraction: observations comparing hæmodynamic effects of atrial and ventricular pacing. Brit. Heart J., 25, 299.

Johansson, B. W., Karnell, J., Malm, A., Sievers, J., and Swedberg, J. (1963). Electrocardiographic studies in patients with an artificial pacemaker. Brit. Heart J., 25, 514.

Lillehei, C. W., Sellers, R. D., Bonnabeau, R. C., and Eliot, R. S. (1963). Chronic postsurgical complete heart block, with particular reference to prognosis, management, and a new P-wave pacemaker. J. thorac. cardiovasc. Surg., 46, 436.

Linenthal, A. J., Zoll, P. M., Garabedian, G. D., and Hubert, K. (1962). Retrograde conduction to the atria from electric stimulation of the ventricles in man. Circulation, 26, 752.

Nathan, D. A., Center, S., Wu, C., and Keller, W. (1963). An implantable synchronous pacemaker for the long term correction of complete heart block. Amer. J. Cardiol., 11, 362.

Nicks, R., Stening, G. F. H., and Hulme, E. C. (1962). Some observations on the surgical treatment of heart block in degenerative heart disease. Med. J. Aust., 2, 857.

Nuñez-Dey, D., Zalter, R., and Eisenberg, H. (1962). Artificially induced parasystole in man due to surgically implanted myocardial pacemaker. Amer. J. Cardiol., 10, 535.

Samet, P., Jacobs, W., Bernstein, W. H., and Shane R. (1963). Hemodynamic sequelæ of idioventricular pacemaking in complete heart block. Amer.J. Cardiol., 11, 594.

Saunders, D. E., Jr., and Ord, J. W. (1962). The hemodynamic effects of paroxysmal supraventricular tachycardia in patients with the Wolff-Parkinson-White syndrome. Amer. J. Cardiol., 9, 223.

Sellers, F. J., Donald, D. E., and Wood, E. H. (1962). Atrial contribution to stroke volume in dogs with chronic cardiac denervation. Physiologist, 5, 211 .

Skinner, N. S., Jr., Mitchell, J. H., Wallace, A. G., and Sarnoff, S. J. (1963). Hemodynamic effects of altering the timing of atrial systole. Amer. J. Physiol., 205, 499.

Sowton, E. (1964a). Hæmodynamic studies in patients with artificial pacemakers. Brit. Heart J., 26, 737.
(1964b). Artificial cardiac pacemaking with particular reference to cardiac physiology. M.D. Thesis, University of Cambridge.

Wiggers, C. J., and Katz, L. N. (1922). The contour of the ventricular volume curves under different conditions. Amer. J. Physiol., 58, 439.

-, and Wégria, R. (1940). Ventricular fibrillation due to single, localized induction and condenser shocks applied during the vulnerable phase of ventricular systole. Amer. J. Physiol., 128, 500.

Zoll, P. M. (1952). Resuscitation of the heart in ventricular standstill by external electric stimulation. New Engl. J. Med., 247, 768 .

—, Frank, H. A., Zarsky, L. R. N., Linenthal, A. J., and Belgard, A. H. (1961). Long-term electric stimulation of the heart for Stokes-Adams disease. Ann. Surg., 154, 330.

- , and Linenthal, A. J. (1960). Long-term electric pacemakers for Stokes-Adams disease. Circulation, 22, 341 . 